\title{
Front Matter: Volume 9804
}

, "Front Matter: Volume 9804," Proc. SPIE 9804, Nondestructive Characterization and Monitoring of Advanced Materials, Aerospace, and Civil Infrastructure 2016, 980401 (1 July 2016); doi: 10.1117/12.2229278 Health Monitoring, 2016, Las Vegas, Nevada, United States 


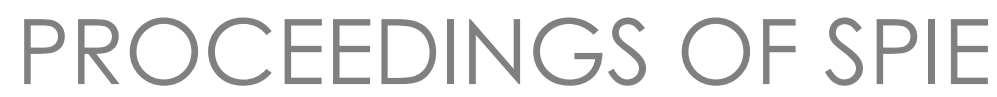

\title{
Nondestructive Characterization and Monitoring of Advanced Materials, Aerospace, and Civil Infrastructure 2016
}

\author{
Tzuyang Yu \\ Andrew L. Gyekenyesi \\ Peter J. Shull \\ H. Felix Wu \\ Editors
}

\section{1-24 March 2016 \\ Las Vegas, Nevada, United States}

Sponsored by

SPIE

Co-sponsored by

Polytec, Inc. (United States) OZ Optics, Ltd. (United States) - APS Dynamics, Inc. (United States) - The ElectroForce Systems Group of TA Electroforce Corporation (United States) • The Institute of Physics (United Kingdom) • American Elements (United States)

Cooperating Organizations

Intelligent Materials Forum (Japan)

Jet Propulsion Laboratory (United States)

National Science Foundation (United States)

Published by

SPIE

Volume 9804 
The papers in this volume were part of the technical conference cited on the cover and title page. Papers were selected and subject to review by the editors and conference program committee. Some conference presentations may not be available for publication. Additional papers and presentation recordings may be available online in the SPIE Digital Library at SPIEDigitallibrary.org.

The papers reflect the work and thoughts of the authors and are published herein as submitted. The publisher is not responsible for the validity of the information or for any outcomes resulting from reliance thereon.

Please use the following format to cite material from these proceedings:

Author(s), "Title of Paper," in Nondestructive Characterization and Monitoring of Advanced Materials, Aerospace, and Civil Infrastructure 2016, edited by Tzu-Yang Yu, Andrew L. Gyekenyesi, Peter J. Shull, H. Felix Wu, Proceedings of SPIE Vol. 9804 (SPIE, Bellingham, WA, 2016) Six-digit Article CID Number.

ISSN: 0277-786X

ISSN: 1996-756X (electronic)

ISBN: 9781510600454

Published by

SPIE

P.O. Box 10, Bellingham, Washington 98227-0010 USA

Telephone +1 3606763290 (Pacific Time) · Fax +1 3606471445

SPIE.org

Copyright (C) 2016, Society of Photo-Optical Instrumentation Engineers.

Copying of material in this book for internal or personal use, or for the internal or personal use of specific clients, beyond the fair use provisions granted by the U.S. Copyright Law is authorized by SPIE subject to payment of copying fees. The Transactional Reporting Service base fee for this volume is $\$ 18.00$ per article (or portion thereof), which should be paid directly to the Copyright Clearance Center (CCC), 222 Rosewood Drive, Danvers, MA 01923. Payment may also be made electronically through CCC Online at copyright.com. Other copying for republication, resale, advertising or promotion, or any form of systematic or multiple reproduction of any material in this book is prohibited except with permission in writing from the publisher. The CCC fee code is 0277-786X/16/\$18.00.

Printed in the United States of America.

Publication of record for individual papers is online in the SPIE Digital Library.

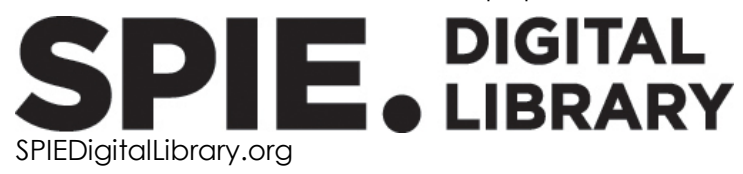

Paper Numbering: Proceedings of SPIE follow an e-First publication model. A unique citation identifier (CID) number is assigned to each article at the time of publication. Utilization of CIDs allows articles to be fully citable as soon as they are published online, and connects the same identifier to all online and print versions of the publication. SPIE uses a six-digit CID article numbering system structured as follows:

- The first four digits correspond to the SPIE volume number.

- The last two digits indicate publication order within the volume using a Base 36 numbering

system employing both numerals and letters. These two-number sets start with 00, 01, 02, 03, 04, 05, 06, 07, 08, 09, OA, OB ... 0Z, followed by 10-1Z, 20-2Z, etc. The CID Number appears on each page of the manuscript. 


\title{
Contents
}

\author{
ix Authors \\ xi Conference Committee \\ $\mathrm{xv}$ Introduction
}

\section{MICROWAVE AND RADAR NDE}

980402 Extracting sparse crack features from correlated background in ground penetrating radar concrete imaging using robust principal component analysis technique [9804-1]

980403 Underground object characterization based on neural networks for ground penetrating radar data [9804-2]

980404 Sizing and ranging criteria for SAR images of steel and wood specimens [9804-3]

\section{NDE/SHM FOR AEROSPACE STRUCTURES}

980408 Ultrasonic guided wave inspection of Inconel 625 brazed lap joints [9804-7]

980409 Fatigue crack growth monitoring of idealized gearbox spline component using acoustic emission [9804-8]

9804 OA A unified formulation for guided-wave propagation in multi-layered mixed anisotropicisotropic hybrid aerospace composites [9804-9]

\section{CIVILIAN SENSING FOR CIVIL INFRASTRUCTURE}

9804 OB Security challenge to using smartphones for SHM [9804-10]

9804 OC Identification of the operational frequencies of $300+$ bridges using smartphones [9804-12]

OPTIMIZATION, SYSTEM IDENTIFICATION, AND SOFT COMPUTING

9804 OD Finite element model updating of a prestressed concrete box girder bridge using subproblem approximation [9804-13]

9804 OE Particle swarm optimization for optimal sensor placement in ultrasonic SHM systems [9804-14] 
9804 OF Dynamic behaviors of historical wrought iron truss bridges: a field testing case study [9804-15]

9804 OG A study of thermal response of concrete towers employing linear regression [9804-16]

\section{KEYNOTE SESSION I}

$9804 \mathrm{OH} \quad$ Laser vibrometry for wind turbines inspection (Keynote Paper) [9804-17]

\section{NDE FOR WIND TURBINES}

9804 Ol Vibration-based damage detection algorithm for WTT structures [9804-18]

9804 0J Dynamic survey of wind turbine vibrations [9804-19]

9804 OK Gearbox fault diagnosis based on time-frequency domain synchronous averaging and feature extraction technique [9804-21]

$9804 \mathrm{OL}$ The nondestructive evaluation of high temperature conditioned concrete in conjunction with acoustic emission and $\mathrm{x}$-ray computed tomography [9804-56]

\section{ULTRASONIC NDE}

9804 OM Piezoceramic omnidirectional transduction of the fundamental shear horizontal guide wave mode [9804-22]

9804 ON Defect detection performance of the UCSD non-contact air-coupled ultrasonic guided wave inspection of rails prototype [9804-23]

9804 OP Quantitative sensing of corroded steel rebar embedded in cement mortar specimens using ultrasonic testing [9804-25]

$98040 Q \quad$ Ultrasonic transmission from fiber optic generators on steel plate [9804-26]

\section{NDE FOR COMPOSITES}

9804 OR Optical transmission scanning for damage quantification in impacted GFRP composites [9804-27]

9804 OS Monitoring chemical degradation of thermally cycled glass-fibre composites using hyperspectral imaging [9804-28]

9804 OT Nonlinear damage detection and localization using a time domain approach [9804-29]

9804 OV An enhanced CCRTM (E-CCRTM) damage imaging technique using a 2D areal scan for composite plates [9804-31] 
9804 OW Health monitoring of composite structures throughout the life cycle [9804-32]

IMAGE AND VIDEO SENSING

980410 Repurposing video recordings for structure motion estimations [9804-35]

980411 Damage detection of concrete masonry structures by enhancing deformation measurement using DIC [9804-36]

980413 Bolt-loosening identification of bolt connections by vision image-based technique [9804-38]

980414 An autonomous unmanned aerial vehicle sensing system for structural health monitoring of bridges [9804-39]

980415 Preparation and characterization of phase change material for thermal energy storage in buildings [9804-90]

NDE FOR OFFSHORE AND RAILROAD STRUCTURES

980416 Health monitoring of offshore structures using wireless sensor network: experimental investigations [9804-40]

\section{LASER AND OPTICAL NDE}

980418 Scanning laser ultrasound and wavenumber spectroscopy for in-process inspection of additively manufactured parts [9804-44]

980419 Nonlinear thermosonics and laser vibrometry for barely visible impact damage of a composite stiffener panel [9804-45]

9804 1A Geometric identification and damage detection of structural elements by terrestrial laser scanner [9804-46]

9804 1C Use of laser reflection technique for defect detection in CFRP-concrete systems [9804-48]

SIGNAL PROCESSING TECHNIQUES IN NDE

9804 1D Improving synthetic aperture focusing technique for thick concrete specimens via frequency banding [9804-49]

9804 IE A novel background subtraction technique based on grayscale morphology for weld defect detection [9804-50]

$9804 \mathrm{IF} \quad$ Lamb wave feature extraction using discrete wavelet transformation and Principal Component Analysis [9804-51] 
9804 IG Frequency domain modeling and dynamic characteristics evaluation of existing wind turbine systems (Keynote Paper) [9804-52]

TIME REVERSAL, NONLINEAR, AND INVERSE PROBLEMS

$980411 \quad$ Modified time reversal imaging of a closed crack based on nonlinear scattering [9804-54]

9804 i J Fast and accurate analytical model to solve inverse problem in SHM using Lamb wave propagation [9804-55]

\section{THERMAL NDE}

$98041 \mathrm{~K}$ A method to measure and estimate normalized contrast in infrared flash thermography [9804-57]

9804 IL Mechanical damage assessment by means of thermo-electrical lock-in thermography [9804-58]

$98041 \mathrm{~N}$ Thermal correlation analysis of a long-span suspension bridge static responses [9804-60]

\section{SENSORS AND SENSING NETWORKS}

9804 1Q Non-destructive testing of critical infrastructure with giant magneto resistive sensors [9804-64]

9804 IR Crack identification for reinforced concrete using PZT based smart rebar active sensing diagnostic network [9804-65]

9804 is Wake-up transceivers for structural health monitoring of bridges [9804-66]

9804 IV Study on monitoring and estimating soil physical properties using piezoceramic transducer [9804-63]

\section{POSTER SESSION}

9804 IW A study on the extraction of the abnormal behavior point using Hilbert-Huang transform [9804-69]

$98041 \mathrm{X}$ Investigating the effect of crack on propagation of ultrasonic guided waves in pipes via wavelet analysis [9804-70]

$98041 \mathrm{Y}$ Comparison and analysis of two modern methods in the structural health monitoring techniques in aerospace [9804-71] 
$98041 \mathrm{Z}$ Photogrammetric analysis of concrete specimens and structures for condition assessment [9804-72]

980420 Decentralized identification of nonlinear structure under strong ground motion using the extended Kalman filter and unscented Kalman filter [9804-73]

980421 Research on quick seismic damage investigation using smartphone [9804-74]

980423 Finite element approach analysis for characteristics of electromagnetic acoustic Lamb wave [9804-76]

980425 Identification of breathing cracks in a beam structure with entropy [9804-79]

980426 Finite element simulation for damage detection of surface rust in steel rebars using elastic waves [9804-80]

980429 Optimum electrode configuration selection for electrical resistance change based damage detection in composites using an effective independence measure [9804-83]

9804 2B Guided wave damage detection with PZT-FBG sensing [9804-85]

9804 2D Non-destructive evaluation of adhesive layer using a planar array capacitive imaging technology [9804-87]

$98042 \mathrm{E} \quad$ A review of nondestructive testing approaches using mechanical and electromagnetic waves [9804-88]

$98042 \mathrm{~F}$ Damage characterization in engineering materials using a combination of optical, acoustic, and thermal techniques [9804-89]

$98042 \mathrm{G}$ Effects of edge grinding and sealing on mechanical properties of machine damaged laminate composites [9804-91]

$98042 \mathrm{H} \quad$ Focusing surface wave imaging with flexible 2D array [9804-1111] 
Proc. of SPIE Vol. $9804980401-8$

Downloaded From: https://www.spiedigitallibrary.org/conference-proceedings-of-spie on 25 Apr 2023 Terms of Use: https://www.spiedigitallibrary.org/terms-of-use 


\title{
Authors
}

Numbers in the index correspond to the last two digits of the six-digit citation identifier (CID) article numbering system used in Proceedings of SPIE. The first four digits reflect the volume number. Base 36 numbering is employed for the last two digits and indicates the order of articles within the volume. Numbers start with 00, 01, 02, 03, 04, 05, 06, 07, 08, 09, OA, OB...0Z, followed by 10-1Z, 20-2Z, etc.

\author{
Abueh, Yeka, OB \\ Ahmadi, Alireza, $1 Y$ \\ Alarifi, Ibrahim M., 2G \\ Alharbi, Abdulaziz, 2G \\ Al-Yahmadi, Amur, $1 \mathrm{~F}$ \\ Aminzadeh, Masoumeh, $1 \mathrm{E}$ \\ Amiryan, Milad, IF \\ Asmatulu, Ramazan, 2G \\ Bahadur, Issam, IF \\ Bailey, J., 1Q \\ Barazanchy, Darun, OA \\ Bartoli, Ivan, 11 \\ Belanger, Pierre, 08, 0M \\ Bi, Siwen, $0 Q$ \\ Blanloevil, Philippe, OE, 1 I \\ Boccardi, S., OT \\ Bocher, Philippe, 08 \\ Boivin, Guillaume, OM \\ Bolhassani, Mohammad, 11 \\ Bond, lan, OW \\ Bondurant, P., 1Q \\ Brownjohn, James M. W., 1N \\ Calla, D.-B., OT \\ Castellanos, Sebastián, OC \\ Chandrasekaran, Srinivasan, 16 \\ Chen, G. W., OD \\ Chen, Gwan-Ying, OL \\ Chen, Lan, $1 \mathrm{~N}$ \\ Chen, Xiaoming, 23 \\ Cheng, Chia-Chi, OJ \\ Cheng, Tao-Ming, OJ \\ Chiang, Chih-Hung, OJ, IG \\ Chilles, James, OW \\ Chitambaram, Thailammai, 16 \\ Choi, Sang-Hoon, Ol \\ Ciampa, Francesco, OT, 19 \\ Clayton, Dwight A., ID \\ Cloud, Gary L., OR \\ Comot, Pierre, 08 \\ Croxford, Anthony, OW \\ Cruz, Alejandro, OC \\ Dai, Kaoshan, OF \\ Dalla, P. T., 2F \\ Dalvi, Aditi, OG \\ D'Amico, Nicolas, 12 \\ Díaz-Montiel, Paulina, 29 \\ Ebert, R., $\mathrm{OH}$ \\ Escalona, Luis, 29 \\ Exarchos, D. A., 1L, 2F
}

Fateh, Mahmood, ON

Flynn, Eric B., 18

Fu, Junqiang, $2 \mathrm{H}$

Ghodsi, Mojtaba, IF

Gholami, Pouya, 1X

Ginzburg, Dmitri, 19

Giurgiutiu, Victor, 0A, $1 \mathrm{~J}$

Groves, R. M., OS

Guinto, Jed A., 11

Hagenbeek, M., OS

Hamid, Ahmad A., 11

Han, Ruicong, 21

Haq, Mahmoodul, OR

Hardman, William, 09

$\mathrm{He}$, Jiaze, OV

Hedric, Andrew, OF

Helmicki, Arthur, OG

Hojjat, Yousef, $1 \mathrm{~F}$

Honarvar, Farhang, IF

Hou, Tsung-Chin, OL, IA

Hsu, Keng-Tsang, OJ

Huang, Chi-Luen, OJ

Huang, Zhenhua, OF

Hunt, Victor, OG

Hunze, A., 1Q

Huston, Dryver, 03

Huynh, Thanh-Canh, 13

Karpenko, Oleksii, OR

Kessler, Seth, 09

Khaloo, Ali, 10

Khomenko, Anton, OR

Kim, Jeong-Tae, 01,13

Kim, Tae-Heon, IW

Kim, Tae-Hwan, Ol

Koenig, S., is

Kokert, J., is

Kontsos, Antonios, 11

Kordatos, E. Z., $1 \mathrm{~L}$

Koricho, Ermias G., OR

Koshti, Ajay M., IK

Koskelo, EliseAnne C., 18

Kumberg, T., is

Kurfess, Thomas, $1 \mathrm{E}$

Lanza di Scalea, Francesco, ON

Lattanzi, David, 10

Lau, Denvid, 1C, 2E

Le, Viet, 04, OP

Li, Hui, 20

Li, Mingchu, 21 
Li, Songsong, 23

$\mathrm{Li}$, Zhe, $2 \mathrm{H}$

Lin, Bin, 2B

Lin, Li-Chiang, $\mathrm{OL}$

Liu, Hong, $\mathrm{OB}$

Liu, Yu-Wei, $1 \mathrm{~A}$

Lo, Tommy, Y., 15

Ma, Qiang, 20

Mactutis, T., $1 Q$

Mahmoudi, Mehdi, IF

Malfense Fierro, Gian Piero, OT, 19

Mariani, Stefano, ON

Marulanda, Johannio, OC

Matikas, T. E., 1L, 2F

Meo, Michele, OT, 19

Müller, B., OS

Nguyen, Thompson $\mathrm{V}$., ON

Nguyen, Tuan-Cuong, $0 \mathrm{l}, 13$

Niezrecki, Christopher, 14

Norouzi, Mehdi, OG

Nurhazli, Nur A. E., OE

Omenzetter, P., OD

OwUsu Twumasi, Jones, 04, OP, OQ

Ozevin, Didem, 09

Pan, Chieh-Chen, 0J

Pan, Huang-Hsing, OL

Papadakis, V. M., OS

Park, Jae-Hyung, 13

Park, Ki-Tae, IW

Peng, Tongxiao, IV

Poddar, Banibrata, $1 \mathrm{~J}$

Preciado, Mónica, OC

Qiu, Qiwen, 1C, 2E

Rajaram, Satish, 11

Reagan, Daniel, 14

Reindl, L. M., is

Riahi, Mohammad, IX, IY

Rose, L. R. Francis, 11

Ryu, Joo-Young, 0l, 13

Sabato, Alessandro, 14

Sidorov, G., $1 Q$

Sinke, J., OS

Song, N. N., 1R

Sternini, Simone, ON

Su, YU-Min, OL, 1A

Sun, Dongtao, 2D

Sun, Xiaoyi, 2B

Tang, Jiong, OK

Tang, Qixiang, 04, OP, 0Q, 26

Tao, Dongwang, 20

Thomson, Peter, OC

Tian, Zhenhua, 2B

Timmons, Alan, 09

Tragazikis, I. K., 2F

Udpa, Lalita, OR

Veidt, Martin, OE, 11

Venkataraman, Satchi, 29

Wang, Chun H., 11

Wang, Ming L., $1 \mathrm{~V}$

Wang, Ruolin, IV
Wang, Shaohan, $2 \mathrm{H}$

Wang, Xingwei, $O Q$

Wang, Ying, OF

Wen, Yintang, 2D

Wilson, Richard, 14

Wilson, Robert, ON

Wimarshana, Buddhi, 25

Wu, Christine, 25

WU, F., IR

Wu, Nan, $0 Q$

Wu, Nan, 25

Xia, Tian, 02,03

Xia, Yong, $1 \mathrm{~N}$

Xiao, Dingguo, $2 \mathrm{H}$

$\mathrm{Xu}$, Chunguang, $2 \mathrm{H}$

Yeoh, Jason, 2G

Younesi, V., 1S

Yu, Chih-Peng, $1 G$

Yu, Lingyu, 2B

Yu, Tzuyang, 04, OP, 0Q, 14, 1Z, 26

Yu, Yan, 21

Yuan, Fuh-Gwo, OV

Zarbaf, Seyed Ehsan Haji Agha Mohammad, OG

Zhang, Lu, 09

Zhang, Shengli, OK

Zhang, Yu, 02, 03

Zhang, Yuyan, 2D

Zhao, Limei, 2D

Zhao, Xuefeng, 21

Zhou, Jingcheng, $O Q$

Zhou, Linren, $1 \mathrm{~N}$

Zhou, Shiyuan, $2 \mathrm{H}$

Zhu, Daopei, $1 \mathrm{~V}$

Ziaiefar, Hamidreza, $1 \mathrm{~F}$ 


\title{
Conference Committee
}

\author{
Symposium Chairs
}

Jayanth N. Kudva, NextGen Aeronautics, Inc. (United States)

Theodoros E. Matikas, University of loannina (Greece)

Symposium Co-chairs

Tribikram Kundu, The University of Arizona (United States)

Gregory W. Reich, Air Force Research Laboratory (United States)

Conference Chair

Tzuyang Yu, University of Massachusetts Lowell (United States)

Conference Co-chairs

Andrew L. Gyekenyesi, Ohio Aerospace Institute (United States)

Peter J. Shull, The Pennsylvania State University (United States)

H. Felix Wu, U.S. Dept. of Energy (United States)

Conference Program Committee

Ralf B. Bergmann, Bremer Institut für angewandte Strahltechnik $\mathrm{GmbH}$ (Germany)

Gary Carr, Federal Railroad Administration (United States)

Genda Chen, Missouri University of Science and Technology

(United States)

Shen-En Chen, The University of North Carolina at Charlotte (United States)

Mohammed M. Ettouney, Weidlinger Associates, Inc. (United States)

Valery F. Godinez-Azcuaga, Shaw Pipeline Services (United States)

Nenad Gucunski, Rutgers, The State University of New Jersey

(United States)

Dryver R. Huston, The University of Vermont (United States)

Xiaoning Jiang, North Carolina State University (United States)

Simon Laflamme, lowa State University (United States)

Denvid Lau, City University of Hong Kong (Hong Kong, China)

Kenneth J. Loh, University of California, Davis (United States)

Jerome P. Lynch, University of Michigan (United States)

Theodoros E. Matikas, University of loannina (Greece)

Oliver J. Myers, Clemson University (United States)

Piotr Omenzetter, University of Aberdeen (United Kingdom)

Didem Ozevin, University of Illinois at Chicago (United States) 
Akira Sasamoto, National Institute of Advanced Industrial Science and Technology (Japan)

Caesar Singh, U.S. Department of Transportation (United States)

Yu-Min Su, National Kaohsiung University of Applied Sciences

(Taiwan)

Yan Wan, University of North Texas (United States)

Ming L. Wang, Northeastern University (United States)

Xingwei Wang, University of Massachusetts Lowell (United States)

Yang Wang, Georgia Institute of Technology (United States)

Fan Wu, Shanghai Jiao Tong University (China)

Tian Xia, The University of Vermont (United States)

Lingyu Yu, University of South Carolina (United States)

Fuh-Gwo Yuan, North Carolina State University (United States)

Paul H. Ziehl, University of South Carolina (United States)

\section{Session Chairs}

1 Microwave and Radar NDE

Tian Xia, The University of Vermont (United States)

Tzuyang Yu, University of Massachusetts Lowell (United States)

2 NDE/SHM for Aerospace Structures

Tzuyang Yu, University of Massachusetts Lowell (United States)

Tian Xia, The University of Vermont (United States)

3 Civilian Sensing for Civil Infrastructure

Piotr Omenzetter, University of Aberdeen (United Kingdom)

Zhenhua Huang, University of North Texas (United States)

4 Optimization, System Identification, and Soft Computing

Piotr Omenzetter, University of Aberdeen (United Kingdom)

Zhenhua Huang, University of North Texas (United States)

5 Keynote Session I

Tzuyang Yu, University of Massachusetts Lowell (United States)

6 NDE for Wind Turbines

Piotr Omenzetter, University of Aberdeen (United Kingdom)

7 Ultrasonic NDE

Tzuyang Yu, University of Massachusetts Lowell (United States)

Yu-Min Su, National Kaohsiung University of Applied Sciences

(Taiwan)

8 NDE for Composites

H. Felix Wu, U.S. Department of Energy (United States)

Lingyu Yu, University of South Carolina (United States) 
9 Keynote Session II

Tzuyang Yu, University of Massachusetts Lowell (United States)

10 Image and Video Sensing

Tian Xia, The University of Vermont (United States)

11 NDE for Offshore and Railroad Structures

Denvid Lau, City University of Hong Kong (Hong Kong, China)

Yu-Min Su, National Kaohsiung University of Applied Sciences (Taiwan)

12 Laser and Optical NDE

Denvid Lau, City University of Hong Kong (Hong Kong, China)

Yu-Min Su, National Kaohsiung University of Applied Sciences (Taiwan)

13 Signal Processing Techniques in NDE

Denvid Lau, City University of Hong Kong (Hong Kong, China)

Yu-Min Su, National Kaohsiung University of Applied Sciences (Taiwan)

14 Keynote Session III

Tzuyang Yu, University of Massachusetts Lowell (United States)

15 Time Reversal, Nonlinear, and Inverse Problems

Genda Chen, Missouri University of Science and Technology (United States)

16 Thermal NDE

Ajay M. Koshti, NASA Johnson Space Center (United States)

Zhu Mao, University of Massachusetts Lowell (United States)

17 Sensors and Sensing Networks

Ming L. Wang, Northeastern University (United States)

Fan Wu, Shanghai Jiao Tong University (China) 
xiv

Proc. of SPIE Vol. $9804980401-14$

Downloaded From: https://www.spiedigitallibrary.org/conference-proceedings-of-spie on 25 Apr 2023 Terms of Use: https://www.spiedigitallibrary.org/terms-of-use 


\section{Introduction}

Aging and deterioration of infrastructure systems (e.g., energy, roads, rail, transit, aviation, dams, bridges, ports, drinking water) are a global challenge facing all countries in the world. In the U.S., the American Society of Civil Engineers (ASCE) estimated an investment of $\$ 3.6$ trillion is needed by 2020 to meet the needs of the nation's business, communities, and people (ASCE 2013 Report Card for America's Infrastructure). Recent incidents such as the drinking water problem in Flint, Michigan and increasing derailments around the nation are examples of this challenge. The pressing issue to the nation is to maintain a resilient and sustainable infrastructure system by developing efficient and effective inspection and repair techniques for various infrastructure systems. It certainly calls for innovative and advanced NDE (nondestructive evaluation) and SHM (structural health monitoring) solutions from the R\&D community.

Highlighted areas in this year's conference include:

- NDE: Microwave and radar, ultrasonic, laser and optical, and thermal

- Applications: Wind turbines, aerospace structures, offshore and railroad structures, and composites

- Signal processing and data interpretation: Optimization, system identification, and soft computing, time reversal, nonlinear, and inverse problems

- Smart sensors: Low power, self-powered, remotely-powered

- Innovative sensing: Civilian sensing, image and video sensing

In this year's conference, we were pleased to have two invited talks from funding agencies to share with us the current and future funding trends in their organizations. These talks were given by Mr. Gary Carr from the U.S. Department of Transportation (DOT) Federal Railroad Administration (FRA) and Dr. H. Felix Wu from the U.S. Department of Energy (DOE) Vehicle Technologies Office (VTO). We were also honored to have two invited keynote speeches given by renowned researchers from Germany (Dr. Reinhard Ebert, Fraunhofer-Institut f"ur Optronik, Systemtechnik und Bildauswertung) and Taiwan (Dr. Chih- Huang Chiang, Chaoyang University of Technology) to talk about the inspection and monitoring of wind turbines under operational and extreme conditions. 
Several areas for future research include:

- NDE/SHM for energy facilities such as wind turbines and nuclear power plants

- Advanced signals processing techniques for improved resolution and damage detectability

- Low power or self-powered sensing networks using energy harvesting from the environment

- Deep subsurface sensing and imaging of reinforced structures using ultrasonic NDE and microwave NDE

On behalf of my colleagues (Andrew Gyekenyesi, Peter J. Shull, and H. Felix Wu), we thank all conference presenters for joining us in this international, annual event for the first time in Las Vegas, Nevada. As always, we welcome prospective researchers to come to the conference and share their exciting research with us!

Tzuyang Yu 